\title{
¿Qué es la «monoparentalidad»? Una revisión crítica de su conceptualización en materia de política social
}

\author{
What is «lone parenthood»? A critical review of its conceptualization \\ in the context of social policy
}

\author{
Manuela AvILÉs HeRnÁNDEZ \\ Universidad de Murcia \\ manoliaviles@um.es
}

Recibido: $30 / 05 / 2015$

Revisado: 25/06/2015

Aceptado: 14/09/2015

Disponible on line: $25 / 11 / 2015$

\section{Resumen}

El uso del concepto «monoparentalidad» se ha intensificado durante los últimos años debido, entre otros, al incremento que de las formas familiares a que hace referencia. A pesar de un uso cada vez más generalizado, la realidad teórica se caracteriza por la falta de un acuerdo global en torno a una cuestión esencial: ¿qué forma familiar es la que debe contener esta categoría sociológica? El problema de la imprecisión teórica normalmente ha afectado al ámbito académico, provocando fuertes discrepancias entre los estudios que se han realizado sobre el tema, y está empezando a tener su repercusión social y legal, de modo que, en materia de Política Social, cada órgano ha elaborado su propia definición Se genera, de este modo, un trato desigual en las múltiples formas de monoparentalidad que las asociaciones y movimientos sociales califican de injusto y discriminatorio.

En este artículo de carácter teórico se identifican y analizan las definiciones legales que se han elaborado durante los últimos años sobre «monoparentalidad» y que se encuentran recogidas en las normativas nacionales y autonómicas diseñadas para la protección social de este tipo de familias. El objetivo es comprobar cómo se conceptualiza el fenómeno familiar en el ordenamiento jurídico español, qué imprecisiones teóricas se observan, y qué similitudes y diferencias terminológicas se dan entre ámbitos territoriales y rangos normativos. Este análisis nos permitirá conocer el significado que se atribuye oficialmente a este tipo de familia en España y aportar claridad sobre el sentido real que se atribuye al término.

Palabras clave: familias monoparentales, clarificación conceptual, análisis socio-jurídico, ordenamiento jurídico español, disposiciones legales.

\begin{abstract}
The use of the concept of «lone parenthood» has intensified during the last years, owing, amongst other things, to the increase in this form of family. In spite of increasingly widespread use, the theoretical reality is characterized by a lack of a global consensus in relation to one essential aspect: What family form should this sociological category comprise? This problem of theoretical imprecision has often affected academia, causing strong discrepancies between different studies. However, it is also starting to have social and legal repercussions, because in terms of social policy each government agency has developed its own definition of the term. As a result, the multiple forms of lone parenthood are treated differently, something which has been described by associations and social movements as unfair and discriminatory.

In this theory-based paper, we analyse some of the official definitions that have been produced in recent years and that are contained in the national and regional regulations created for the social protection of such families. The objective is to identify the conceptualization of this family phenomenon in the Spanish legal system, the existence of theoretical imprecisions and the similarities and differences that exist between territorial areas and legal statuses. This analysis helps us to clarify the official meaning attributed to these families in Spain and to provide clarity regarding this imprecise concept. Keywords: lone-parent families, conceptual clarification, socio-legal analysis, Spanish legal system, legal provisions.
\end{abstract}

Referencia normalizada: Avilés Hernández, M. (2015): «¿Qué es la “monoparentalidad”? Una revisión crítica de su conceptualización en materia de política social». Cuadernos de Trabajo Social, 28(2): 211-223.

Sumario: 1. Monoparentalidad: un término frecuente, poco consensuado. 2. La monoparentalidad en el ordenamiento jurídico español. 3. Revisión teórica de los criterios más recurrentes en las definiciones legales. 4. Otros criterios para incluir en la explicación legal de «monoparental». 5. Conclusiones y discusión. 6. Referencias bibliográficas. 


\section{Monoparentalidad: un término frecuen- te, poco consensuado}

Aunque las situaciones monoparentales han estado presentes a lo largo de toda la historia, el concepto que se utiliza en la actualidad para referirse a ellas es joven (Avilés, 2013). Su reciente aparición, así como la celeridad con la que se ha extendido en determinados países occidentales, a consecuencia del incremento desmesurado en el número de rupturas conyugales y nacimientos fuera del matrimonio, ha dificultado la construcción de una única definición cultural operativa que permita convenir, en todos los sentidos, a qué realidad familiar se está haciendo exactamente referencia cuando se habla de monoparentalidad.

La comunidad científica es la que normalmente se ha preocupado por la clarificación conceptual de esta expresión y por denunciar los problemas que, a efectos empíricos, conlleva la falta de un acuerdo global en torno a su significado (Roll, 1991; Iglesias de Ussel, 1988, 1994, 1998; Fernández Cordón y Tobío Soler, 1998, 1999; Barrón, 2002; Rodríguez y Luengo, 2003; 2011; Almeda et al., 2010; Almeda y Di Nella, 2011; Avilés, 2015). Los teóricos que se han interesado por este aspecto han coincidido en señalar que existe una definición mínima de monoparentalidad, que la entiende como aquella situación de convivencia en la que un único progenitor, normalmente la madre, asume en solitario el cuidado de sus hijos/as por motivos tan diversos como la viudedad o la ruptura conyugal. En la tradición intelectual que afronta este concepto existe, por tanto, un cierto consenso, al señalar que, en cualquier estructura familiar de corte monoparental, debe existir necesariamente un solo progenitor, que asume la jefatura o responsabilidad principal del núcleo, y su hijo o hija dependiente, sobre todo en términos económicos y emocionales, a cargo de dicho progenitor. Las controversias surgen al intentar precisar qué se entiende por jefatura del núcleo, hijo/a dependiente, a cargo del progenitor, etc., y al abordar cuestiones complementarias como la presencia de otras personas en la vivienda, la posible implicación personal y económica del progenitor no conviviente en el cuidado del hijo/a, los motivos que originan la entrada en una situación de monoparentalidad, etc.
Con el incremento de situaciones monoparentales y la adopción por los órganos públicos de medidas puntuales que buscan garantizar la protección social de estas familias, el debate sobre qué es la monoparentalidad se ha hecho extensible a otros sectores de nuestra sociedad, como el jurídico y legal. Cuando hace unos años, por ejemplo, algunas comunidades autónomas, como Andalucía y Cataluña, decidieron que los niños/as de familias monoparentales obtuvieran una puntuación adicional en el baremo de acceso a los centros educativos, las dudas e interrogantes sobre cuándo una familia debía ser considerada monoparental aparecieron en la Administración Pública y entre las propias familias que, por primera vez en muchos casos, tuvieron que plantearse una pregunta: ¿soy monoparental? Esa misma cuestión, o una parecida, ¿qué características debe tener el grupo familiar para ser monoparental?, se hizo presente también en la esfera jurídica, ya que varias familias pensaron que se habían vulnerado sus derechos civiles y sociales, al no considerarlas monoparentales cuando, en su opinión, lo eran. Los tribunales se vieron entonces en la obligación de revisar el ordenamiento jurídico, con el fin de obtener las distintas definiciones legales que se habían ofrecido al respecto, y poder sentenciar así de la manera más acertada y justa posible, a veces en contra de lo que la propia Administración Pública había dictaminado previamente ${ }^{1}$.

Estos hechos evidencian algunos de los problemas que, a efectos prácticos, empiezan a aparecer en nuestro país como consecuencia de la falta de precisión teórica que caracteriza al término que nos ocupa. Las propias asociaciones y movimientos sociales se han pronunciado al respecto, denunciando públicamente las consecuencias que derivan de esta situación. Según exponen, la falta de consenso a escala nacional, además de generar confusión, hace que cada organismo autonómico defina este concepto de una manera, provocando un trato diferenciado entre las situaciones de monoparentalidad en base a la zona geográfica de residencia, hecho que califican de injusto y poco democrático.

Buscando aportar claridad al debate social emergente, en este artículo se propone una revi-

\footnotetext{
${ }^{1}$ Un ejemplo de esta situación se encuentra en la Sentencia 141, de 6 de mayo de 2010, que dictó el Juzgado de lo Contencioso Administrativo núm. 12 de Sevilla (recuperado de http://www.legaltoday.com/ files/File/pdfs/ familia-monoparental.pdf).
} 
sión teórica de este concepto, utilizando para ello las definiciones oficiales que se han elaborado durante los últimos años. Estas definiciones se encuentran recogidas en las normativas diseñadas para la protección social de estas familias. A través de su análisis comparado se pretende dar respuesta, entre otros, a los siguientes interrogantes: cómo conceptualiza el ordenamiento jurídico español este fenómeno familiar, qué imprecisiones teóricas se observan al respecto, y qué similitudes y diferencias se dan entre ámbitos territoriales (estatal y autonómico) y rangos normativos (principalmente reales decretos y leyes). Este análisis nos permitirá conocer el significado oficial que se atribuye a este tipo de familia en España y aportar claridad sobre el sentido real del término.

Atendiendo a la estructura del artículo, se presentan, en primer lugar, las definiciones que se han encontrado en la legislación española sobre el fenómeno de la monoparentalidad, y que son las que van a servir de base para el análisis que se propone. A continuación, se examinan los criterios conceptuales que éstas utilizan, identificando posibles imprecisiones o ambigüedades teóricas con respecto a las consideraciones que se han hecho desde la literatura sociológica. Después se exponen una serie de criterios que no están presentes en estas definiciones pero cuya inclusión sería recomendable, pues favorecería que las políticas sociales se implementaran con mayor rigor. Finalmente, se concluye el análisis presentando, a modo de debate, las ideas generales que se desprenden del mismo, así como una serie de propuestas que evitarían los problemas prácticos que, a efectos legales, derivan de la falta de precisión teórica que caracteriza al término.

\section{La monoparentalidad en el ordenamiento jurídico español}

Para el análisis que se propone se ha tomado como referencia el Boletín Oficial del Estado (BOE), concretamente su base de datos de legislación (https://www.boe.es/legislacion/), donde se recoge la normativa vigente consolidada tanto a nivel nacional como autonómico. En términos nacionales, la base de datos recoge la legislación que afecta al ámbito general del Estado desde 1960. Por comu- nidades autónomas, ofrece las leyes y decretos legislativos publicados desde 1980. También incluye la normativa europea desde 1952, que ha quedado excluida del análisis atendiendo a la propia esencia de éste, que pretende un enfoque nacional.

Como descriptores para la búsqueda se han empleado los términos de «monoparentalidad», «monoparental»y «monoparentales». El primero se ha seleccionado porque es el concepto que se utiliza para designar este fenómeno familiar en su conjunto; los dos restantes porque son adjetivos generales que caracterizan al grupo e indican su naturaleza. Se podrían haber empleado en su lugar otros más específicos, como «familia monoparental», pero se ha optado por estos para hacer así más amplia la búsqueda de normativa. Los resultados, no obstante, evidencian que la legislación española tiende a emplear el término «monoparental» en relación con el de «familia». En escasas ocasiones se habla de «hogar monoparental» o «núcleo monoparental». Tampoco se usa con frecuencia la expresión monoparentalidad; apenas se han obtenido resultados en este sentido.

Tras consultar la base de datos, encontramos que son 162 las disposiciones de carácter general que, en su texto, mencionan alguno de estos términos. De ellas, el 8,6 por ciento están derogadas, mientras que el resto se mantienen vigentes. La primera que habla en sus páginas de este fenómeno familiar es el Real Decreto 195, de 1989, emitido por el Ministerio de Relaciones con las Cortes y de la Secretaría del Gobierno (BOE núm. 48, de 25 de febrero de 1989, pp. 5.533-5.534). Esta norma tiene por objeto establecer los procedimientos que deben seguirse para solicitar ayudas destinadas a fines de interés social, derivadas de la asignación tributaria del Impuesto sobre la Renta de las Personas Físicas. En su artículo tercero señala que las ayudas se concederán a programas de cooperación y voluntariado social de ámbito estatal, dirigidos, entre otros colectivos, a las familias monoparentales. Es, por lo tanto, la primera vez que este tipo de familias aparecen como tales, es decir, con su nomenclatura posmoderna en nuestro ordenamiento jurídico ${ }^{2}$. A partir de ese momento, la referencia explícita a este tipo de familias se va haciendo presente pero de manera puntual. De he-

\footnotetext{
${ }^{2}$ Anterior a esta norma se encuentra el Real Decreto Legislativo 670, de 1987, emitido por el Ministerio de Economía y Hacienda (BOE núm. 126, de 27 de mayo de 1987, pp. 15.598 a 15.610). Sin embargo, en este caso, el concepto «monoparentales» se incluye en el texto consolidado, actualizado a 30 de diciembre de 2014 , y no en la normativa original.
} 
cho, apenas el 9,3 por ciento de las normas encontradas pertenecen a los años noventa. Realmente es en el siglo XXI, sobre todo a partir de 2004, cuando estas familias se abren paso en la legislación española. Prueba de ello es que casi el 81 por ciento de las disposiciones corresponden al periodo 2004-2015. La más actual es el Real Decretoley 1/2015 (BOE núm. 51, de 28 de febrero de 2015, pp. 19.058-19.101), por el que se aprueban una serie de medidas de orden social, destinadas a beneficiar, entre otras, a las familias monoparentales con dos hijos/as a cargo.

En base al ámbito territorial, el 45,1 por ciento de las disposiciones son estatales y el 54,9 por ciento son autonómicas. Si la atención se centra en las estatales (en total 73), más de la mitad se reparte entre tres departamentos: la Jefatura del Estado con 16, lo que supone el 21,9 por ciento de las estatales, el Ministerio de Economía y Hacienda con 13, esto es el 17,8 por ciento, y el Ministerio de Trabajo y Asuntos Sociales con 12, que equivalen al 16,4 por ciento. Por comunidades autónomas, prácticamente una de cada cuatro fueron emitidas por Cataluña (en total $21 \mathrm{de}$ las 89 normas autonómicas, lo que supone el 23,6 por ciento de éstas). Aragón con 12 (13,5 por ciento), Castilla y León con 10 (11,2 por ciento), Andalucía con 9 (10,1 por ciento) y Galicia con 8 (9 por ciento), completan el listado de comunidades con mayor número de disposiciones generales de ámbito autonómico en las que se hace referencia explícita al fenómeno de la monoparentalidad.

En lo que al rango se refiere, y dada la naturaleza de la base de datos con la que se está trabajando, la mayoría son leyes, en concreto el 58 por ciento. El resto son reales decretos (el 14,2 por ciento), resoluciones (el 9,3 por ciento) y órdenes (el 8 por ciento), principalmente. A nivel estatal, una de cada tres disposiciones son reales decretos, mientras que en el ámbito autonómico la mayoría son leyes.

Si se revisa el contenido de las 162 normativas, observamos que en escasas ocasiones se ofrece una definición del fenómeno que nos ocupa. Tan sólo 18, esto es el 11,1 por ciento, recogen en su texto el significado concreto que atribuyen a este tipo de familias. De ellas, 5 son estatales y 13 autonómicas. La mayoría están concentradas en un mismo periodo de tiempo, entre los años 2006 y 2015. Esto evidencia una falta de precisión teórica en el ámbito legal, que dificulta la implementación de las medidas que se diseñan desde los órganos legislativos, provocando confusión entre las familias y el propio personal encargado de su aplicación. A continuación se recogen las 18 definiciones que se han encontrado, agrupadas por ámbito territorial y orden cronológico (Cuadro 1).

\begin{tabular}{|c|c|}
\hline \multicolumn{2}{|c|}{ Estatales } \\
\hline Disposición & Definición \\
\hline $\begin{array}{l}\text { Ley } 35 / 2007 \text {, de } 15 \text { de noviembre, por la que se es- } \\
\text { tablece la deducción por nacimiento o adopción en } \\
\text { el Impuesto sobre la Renta de las Personas Físicas } \\
\text { y la prestación económica de pago único de la Se- } \\
\text { guridad Social por nacimiento o adopción (BOE } \\
\text { núm. } 275 \text {, de } 16 \text { de noviembre de } 2007 \text {, p. } 46.990 \text { ). }\end{array}$ & $\begin{array}{l}\text { «...la constituida por un solo progenitor con el } \\
\text { que convive el hijo nacido o adoptado y que } \\
\text { constituye el sustentador único de la familia» }{ }^{1} \text {. }\end{array}$ \\
\hline $\begin{array}{l}\text { Real Decreto 2066/2008, de } 12 \text { de diciembre, por } \\
\text { el que se regula el Plan Estatal de Vivienda y Re- } \\
\text { habilitación 2009-2012 (BOE núm. 309, de } 24 \text { de } \\
\text { diciembre de 2008, p. 51.935). }\end{array}$ & $\begin{array}{l}\text { «...la constituida por el padre o la madre y el o } \\
\text { los hijos». }\end{array}$ \\
\hline \multicolumn{2}{|c|}{ Autonómicas } \\
\hline Disposición & Definición \\
\hline $\begin{array}{l}\text { Ley } 18 / 2003 \text {, de } 4 \text { de julio, de Apoyo a las Fami- } \\
\text { lias (BOE núm. } 189 \text {, de } 8 \text { de agosto de } 2003 \text {, p. } \\
30.700 \text { ) (Cataluña). }\end{array}$ & $\begin{array}{l}\text { «...una familia con niños menores que conviven } \\
\text { en la misma y que dependen económicamente de } \\
\text { una sola persona». }\end{array}$ \\
\hline
\end{tabular}




\begin{tabular}{|c|c|}
\hline \multicolumn{2}{|c|}{ Autonómicas } \\
\hline Disposición & Definición \\
\hline \multirow{2}{*}{$\begin{array}{l}\text { Ley } 12 / 2006 \text {, de } 27 \text { de diciembre, sobre fiscalidad } \\
\text { complementaria del Presupuesto de la Comunidad } \\
\text { Autónoma de Andalucía (BOE núm. 14, de } 16 \text { de } \\
\text { enero de } 2007 \text {, p. } 2.165 \text { ) (Andalucía). }\end{array}$} & $\begin{array}{l}\text { «...la formada por la madre o el padre y todos los } \\
\text { hijos que convivan con uno u otro y que reúnan } \\
\text { los siguientes requisitos: }\end{array}$ \\
\hline & $\begin{array}{l}\text { a) Hijos menores de edad, con excepción de los } \\
\text { que, con el consentimiento de los padres, vivan } \\
\text { independientes de éstos. } \\
\text { b) Hijos mayores de edad incapacitados judi- } \\
\text { cialmente sujetos a patria potestad prorrogada o } \\
\text { rehabilitada» }{ }^{2} \text {. }\end{array}$ \\
\hline $\begin{array}{l}\text { Ley } 1 / 2007 \text {, de } 7 \text { de marzo, de Medidas de Apoyo } \\
\text { a las Familias de la Comunidad de Castilla y León } \\
\text { (BOE núm. } 76 \text {, de } 29 \text { de marzo de } 2007 \text {, p. } \\
\text { 13.658) (Castilla y León). }\end{array}$ & $\begin{array}{l}\text { «...las unidades familiares con hijos menores, o } \\
\text { mayores de edad en situación de dependencia, } \\
\text { que se encuentren a cargo de un único responsa- } \\
\text { ble familiar». }\end{array}$ \\
\hline $\begin{array}{l}\text { Ley } 18 / 2008 \text {, de } 23 \text { de diciembre, para la Garantía } \\
\text { de Ingresos y para la Inclusión Social (BOE núm. } \\
242 \text {, de } 7 \text { de octubre de 2011, p. 10.5505) (País } \\
\text { Vasco). }\end{array}$ & $\begin{array}{l}\text { «...las constituidas por la madre o el padre con } \\
\text { uno o varios hijos o hijas a su cargo y sin rela- } \\
\text { ción conyugal o análoga en el momento de soli- } \\
\text { citud de la presentación». }\end{array}$ \\
\hline \multirow[t]{3}{*}{$\begin{array}{l}\text { Ley } 6 / 2008 \text {, de } 30 \text { de diciembre, de Medidas Pre- } \\
\text { supuestarias, Administrativas y Tributarias de } \\
\text { acompañamiento a los presupuestos Generales pa- } \\
\text { ra } 2009 \text { (BOE núm. } 68 \text {, de } 20 \text { de marzo de } 2009 \text {, } \\
\text { p. 27.754) (Principado de Asturias). }\end{array}$} & $\begin{array}{l}\text { «...contribuyente que tenga a su cargo descen- } \\
\text { dientes, siempre que no conviva con cualquier } \\
\text { otra persona ajena a los citados descendientes, } \\
\text { salvo que se trate de ascendientes (...). Se consi- } \\
\text { derarán descendientes a los efectos de la presen- } \\
\text { te deducción: }\end{array}$ \\
\hline & $\begin{array}{l}\text { a) Los hijos menores de edad, tanto por relación de } \\
\text { paternidad como de adopción, siempre que convi- } \\
\text { van con el contribuyente y no tengan rentas anua- } \\
\text { les, excluidas las exentas, superiores a } 8.000 \text { euros. } \\
\text { b) Los hijos mayores de edad discapacitados, } \\
\text { tanto por relación de paternidad como de adop- } \\
\text { ción, siempre que convivan con el contribuyente } \\
\text { y no tengan rentas anuales, excluidas las exentas, } \\
\text { superiores a } 8.000 \text { euros. } \\
\text { c) Los descendientes a que se refieren los apar- } \\
\text { tados a) y b) anteriores que, sin convivir con el } \\
\text { contribuyente, dependan económicamente de él } \\
\text { y estén internados en centros especializados. }\end{array}$ \\
\hline & $\begin{array}{l}\text { Se asimilarán a descendientes aquellas personas } \\
\text { vinculadas al contribuyente por razón de tutela y } \\
\text { acogimiento }(\ldots))^{3} \text {. }\end{array}$ \\
\hline \multirow{2}{*}{$\begin{array}{l}\text { Ley } 19 / 2010 \text {, de } 28 \text { de diciembre, de medidas tri- } \\
\text { butarias y administrativas de la Comunidad Autó- } \\
\text { noma de Extremadura (BOE núm. 19, de } 22 \text { de } \\
\text { enero de 2011, p. } 7.021 \text { ) (Extremadura). }\end{array}$} & $\begin{array}{l}\text { «...la madre o el padre y los hijos que convivan } \\
\text { con una u otro y que reúnan alguno de los si- } \\
\text { guientes requisitos: }\end{array}$ \\
\hline & $\begin{array}{l}\text { a) Los hijos menores de edad con excepción de } \\
\text { los menores emancipados. } \\
\text { b) Hijos mayores de edad incapacitados judicial- } \\
\text { mente sujetos a patria potestad prorrogada o re- } \\
\text { habilitada». }\end{array}$ \\
\hline
\end{tabular}




\begin{tabular}{|l|l|}
\hline \multicolumn{2}{|c|}{ Autonómicas } \\
\hline \multicolumn{1}{|c|}{ Disposición } & \multicolumn{1}{c|}{ Definición } \\
\hline $\begin{array}{l}\text { Ley } 3 / 2011, \text { de } 30 \text { de junio, de apoyo a la familia } \\
30 \text { de julio de 2011, p. 86.821) (Galicia). }\end{array}$ & $\begin{array}{l}\text { «...núcleo familiar compuesto por un único pro- } \\
\text { genitor o progenitora que no conviva con otra } \\
\text { persona con la que mantenga una relación análo- } \\
\text { ga a la conyugal y los hijos o hijas menores a su } \\
\text { cargo, siempre que el otro progenitor o progeni- } \\
\text { tora no contribuya económicamente a su susten- } \\
\text { to. A estos efectos, tienen la misma considera- } \\
\text { ción que el hijo o hija: }\end{array}$ \\
$\begin{array}{l}\text { 1. Las personas unidas al único progenitor o } \\
\text { progenitora en razón de tutela o acogimiento. } \\
\text { 2. El concebido o concebida, siempre que me- } \\
\text { diante la aplicación de esta asimilación se obten- } \\
\text { ga mayor beneficio». }\end{array}$ \\
\hline $\begin{array}{l}\text { Ley 9/2014, de 23 de octubre, de Apoyo a las Fa- } \\
\text { milias de Aragón (BOE núm. 281, de 20 de no- } \\
\text { viembre de 2014, p. 94.846) (Aragón). }\end{array}$ & $\begin{array}{l}\text { «...núcleo familiar compuesto por un único pro- } \\
\text { genitor, que no conviva con su cónyuge ni con } \\
\text { otra persona con la que mantenga una relación } \\
\text { análoga a la conyugal, y los hijos a su cargo, } \\
\text { siempre que constituya el único sustentador de la } \\
\text { familia». }\end{array}$ \\
\hline
\end{tabular}

${ }^{1}$ Esta misma definición aparece también en las siguientes disposiciones de ámbito estatal: Ley 2/2008, de 23 de diciembre, de Presupuestos Generales del Estado para el año 2009 (BOE núm. 309, de 24 de diciembre de 2008, p. 51.860); Real Decreto 295/2009, de 6 de marzo, por el que se regulan las prestaciones económicas del sistema de la Seguridad Social por maternidad, paternidad, riesgo durante el embarazo y riesgo durante la lactancia natural (BOE núm. 69, de 21 de marzo de 2009, p. 27.954); Orden $\mathrm{DEF} / 253 / 2015$, de 9 de febrero, por la que se regula el régimen de vacaciones, permisos, reducciones de jornada y licencias de los miembros de las Fuerzas Armadas (BOE núm. 42, de 18 de febrero de 2015, p. 13.201).

${ }_{2}^{2}$ Esta definición aparece también en las siguientes disposiciones de ámbito autonómico, todas ellas emitidas por el mismo Departamento, la Comunidad Autónoma de Andalucía: Ley 1/2008, de 27 de noviembre, de medidas tributarias y financieras de impulso a la actividad económica de Andalucía, y de agilización de procedimientos administrativos (BOE núm. 309, de 24 de diciembre de 2008, p. 51.939); Decreto Legislativo $1 / 2009$, de 1 de septiembre, por el que se aprueba el texto refundido de las disposiciones dictadas por la Comunidad Autónoma de Andalucía en materia de tributos cedidos (BOE núm. 229, de 22 de septiembre de 2009, p. 78.809).

${ }^{3}$ Esta definición aparece también en las siguientes disposiciones de ámbito autonómico, todas ellas emitidas por el mismo Departamento, Comunidad Autónoma del Principado de Asturias: Ley 4/2009, de 29 de diciembre, de Medidas Administrativas y Tributarias de Acompañamiento a los Presupuestos Generales para 2010 (BOE núm. 53, de 2 de marzo de 2010, p. 20.418); Ley 13/2010, de 28 de diciembre, de medidas presupuestarias y tributarias de acompañamiento a los Presupuestos Generales para 2011 (BOE núm. 57, de 8 de marzo de 2011, pp. 26.061-26.062); Decreto Legislativo 2/2014, de 22 de octubre, por el que se aprueba el texto refundido de las disposiciones legales del Principado de Asturias en materia de tributos cedidos por el Estado (BOE núm. 29, de 3 de febrero de 2015, p. 8.135).

${ }^{4}$ Esta normativa habilita expresamente al Departamento competente en materia de familia a regular mediante orden los requisitos necesarios para la calificación de familia monoparental (Disposición final segunda). De las 162 normativas, es la única que en su texto incorpora, además de "monoparental", el concepto de "familias monomarentales", que está empezando a abrirse paso en el ámbito académico (Avilés, 2013).

Fuente: Elaboración propia.

Cuadro 1. Definiciones legales sobre la condición de «monoparental». 
De la información que contiene el Cuadro 1 se desprenden dos ideas fundamentales: la primera es que son las comunidades autónomas las que ofrecen en la mayoría de los casos una definición de monoparental. De hecho, a nivel estatal apenas se clarifica este fenómeno y, cuando se hace, la definición resulta ambigua. La segunda es que cada comunidad tiende a ser coherente en su propio ordenamiento interno (véanse las notas al pie del cuadro), utilizando siempre la misma conceptualización, aspecto que resulta sumamente positivo. Esto, sin embargo, no exime que, como denuncian las asociaciones de familias monoparentales, se den diferencias entre zonas geográficas. Es decir, una misma familia, dependiendo de la comunidad autónoma a la que pertenezca, puede ser monoparental o no, todo depende de la definición que rija, en el ámbito legal, en su lugar de residencia. En el cuadro se puede apreciar esa falta de consenso entre comunidades; tan sólo Andalucía y Extremadura coinciden, grosso modo, en la conceptualización. El Principado de Asturias es, por su parte, la que ofrece una mayor precisión en su definición.

\section{Revisión teórica de los criterios más recu- rrentes en las definiciones legales}

Tras identificar las definiciones que ofrece la legislación española sobre la condición de monoparental, vemos que la mayoría coincide con la noción básica o mínima que rige en el ámbito científico. Aún así, incluyen matices que conviene revisar y contrastar con la literatura existente. Se ha realizado, para ello, un análisis de contenido, cuyos resultados se exponen a continuación.

\subsection{Presencia de un solo progenitor o respon- sable}

Todas las definiciones coinciden en señalar que uno de los requisitos indispensables para que una estructura sea monoparental es la presencia de un único progenitor o responsable en ella. Las definiciones hablan concretamente de la existencia de un solo progenitor (Ley 35/2007; Ley 9/2014), una sola persona (Ley 18/2003), un único responsable familiar (Ley 9/2007), etc.

Junto a esto, las normas autonómicas más recientes, las leyes $3 / 2011$ y $9 / 2014$, señalan que esta persona no puede convivir con su actual pareja sentimental, pues, de hacerlo, esa estructura perdería su condición de monoparental. Algo parecido indica la ley 6/2008, donde se apunta que el contribuyente no podrá convivir «con cualquier otra persona ajena a los descendientes, salvo que se trate de (los) ascendientes») de dicho contribuyente (p. 27754). Incorporar este aspecto en las definiciones resulta acertado, a la vez que necesario, ya que si la nueva pareja del progenitor pasa a convivir con el núcleo monoparental, o viceversa, la relación entre los adultos se formaliza, y el grupo se convierte en lo que actualmente se conoce como una familia reconstituida o recompuesta. En el ámbito científico, es común incluir este aspecto en las definiciones; sin embargo, esto no siempre sucede en el ámbito legal, como puede apreciarse. Nos encontramos, por lo tanto, ante una de las primeras imprecisiones teóricas que se dan en este sentido.

Algunas leyes, como la 18/2008, van más allá y apuntan que el progenitor no podrá tener una relación conyugal o análoga en el momento de solicitud. Este criterio es más restrictivo que el anterior y puede ser pertinente en función de lo que regule la normativa pero no necesariamente definitorio de una situación de monoparentalidad. Es decir, el grupo podría, en términos generales, seguir siendo monoparental aunque el progenitor responsable tuviera una nueva pareja, incluso si ésta es el otro progenitor de los hijos/as, siempre y cuando no conviva con ella.

En relación a la presencia en la vivienda de otras personas diferentes a la pareja sentimental del progenitor, sólo la ley 6/2008 contempla, como ya se ha señalado, la posibilidad de que miembros de la familia extensa, en este caso los ascendientes del responsable familiar, convivan junto al núcleo. Las definiciones restantes no se posicionan en este sentido, generando nuevamente cierta ambigüedad. En el ámbito científico, hay una diferencia importante entre países. En la zona anglosajona, se entiende que el grupo será monoparental cuando viva solo; si lo hace junto a otras personas pierde su condición. En Latinoamérica y la zona del Mediterráneo, la presencia de otras personas en la vivienda no suele desposeer al núcleo de su condición monoparental. De hecho, en España existen matices terminológicos para referirse a ambas situaciones. Uno de los más utilizados distingue entre monoparentalidad simple, cuando el grupo monoparental vive solo, y monoparentalidad compleja o compuesta, cuando lo hace con amigos/as y/o miembros de la familia extensa. Para Flaquer, Almeda y Navarro-Varas (2006) 
diferenciar entre ambos tipos resulta muy pertinente en un país como España, donde una parte significativa de núcleos monoparentales conviven con sus ascendientes, generando, por lo tanto, una situación familiar compleja. Teniendo en cuenta la crisis socioeconómica por la que atraviesa nuestra sociedad y el aumento de situaciones de dependencia como consecuencia del envejecimiento, sería recomendable que también las definiciones legales hicieran referencia expresa a ambas formas de monoparentalidad o, al menos, a la posibilidad de que otros miembros de la familia extensa, y/o conocidos, habiten en esa misma vivienda.

Además de estos aspectos, y vinculado con el papel que el progenitor desempeña dentro del grupo familiar, las leyes 35/2007 y 9/2014, la primera de ámbito estatal y la segunda autonómica, señalan que será el sustentador único de la familia. La ley 18/2003 apunta, en relación con esta misma idea, que los hijos/as conviven y dependen económicamente de una sola persona, que en la mayoría de los casos será el padre o la madre con la que conviven. Otras definiciones, como las que aparecen en las leyes $1 / 2007$, $18 / 2008,6 / 2008$ y 3/2011, especifican que los hijos/as se encuentran a cargo del progenitor, indicando así que están bajo su responsabilidad. En casi todas las definiciones, por lo tanto, se apunta similar idea: el padre o madre monoparental es el principal responsable de los hijos/as, asumiendo la jefatura del grupo. Si en el resto de definiciones no se especifica este requisito es porque, de alguna manera, queda implícito en la propia definición de monoparental. De hecho, más que un requisito, es una obligación inherente al hecho de ser el único progenitor. Por lo tanto, la condición de monoparental conlleva no sólo la presencia de un único progenitor sin pareja cohabitante en la estructura, sino también el ejercicio, por parte de éste, de la jefatura del grupo monoparental. Esto, apunta Vela (2005), supone asumir el grueso de las labores diarias y la responsabilidad de la mayor parte de las cuestiones que afectan a los miembros que componen el grupo. En definitiva, desempeñar «un liderazgo emocional y material» (p. 3) con respecto a los hijos/as, quienes dependen social y económicamente de ese adulto.

La ley 3/2011 es la única que menciona al progenitor no cohabitante, señalando que éste no puede contribuir al sustento económico del gru- po familiar. Con esta premisa la normativa enfatiza aún más el hecho de que el progenitor monoparental es el único responsable, a todos los efectos, del grupo familiar. En la conceptualización académica de la monoparentalidad es difícil precisar con exactitud cuál es el papel del progenitor no cohabitante. Habrá casos en los que éste no tenga contacto con sus hijos/as, bien porque no quiere, bien porque ha fallecido, o bien porque no existe, como sucede cuando se recurre a una fecundación asistida o adopción. Sin embargo, en otras ocasiones habrá progenitores que no habiten junto a sus hijos/as pero siguen teniendo un contacto regular con ellos e, incluso, están implicados activamente en los aspectos que les afectan. No se puede afirmar, por lo tanto, que la falta de relación entre el progenitor no cohabitante y sus hijos/as sea un requisito de monoparentalidad, pero tampoco se puede negar. Sólo es posible aclarar que existe una falta de consenso en relación a este aspecto. Las pocas definiciones que lo tienen en cuenta pertenecen al ámbito jurídico, $\mathrm{y}$ lo incorporan de forma puntual para regular alguna ayuda o beneficio concreto, como sucede en la ley 3/2011. Las definiciones científicas, por su parte, no se pronuncian al respecto, hecho del cual se deduce que las/los investigadores aceptan que el progenitor no cohabitante pueda estar implicado en las relaciones y actividades familiares. Es más, se suele plantear que, aunque el progenitor no conviviente se relacione con el grupo familiar y contribuya económicamente a su sustento a través por ejemplo de una pensión de alimentos, la responsabilidad final, así como las decisiones cotidianas y la gestión de las actividades domésticas, entre otras cosas, recaen en última instancia sobre el progenitor que se encuentra en el núcleo, por lo que, en sentido estricto, se entiende que los hijos/as están a cargo de un único progenitor, aquel con el que conviven.

\subsection{Presencia de hijos/as dependientes}

Si un único progenitor o responsable en el grupo se constituye como uno de los elementos esenciales al hablar de monoparentalidad, la existencia de uno o varios hijos/as en ese mismo grupo va a suponer el segundo de los requisitos necesarios. Así lo señalan todas las disposiciones legales recogidas en el cuadro. Las leyes 35/2007, $6 / 2008$ y $3 / 2011$, especifican además que podrán ser nacidos, adoptados o estar bajo la tutela o acogimiento de ese adulto responsable. 
Además de su presencia, es necesario que sean dependientes del progenitor con el que conviven, o se encuentren a su cargo. Las normativas que mencionan este aspecto, todas ellas autonómicas, toman como referencia la edad de los hijos/as para determinar su grado de dependencia. En general, entienden por hijo/a dependiente aquel que es menor de edad. Fijar el límite en los 18 años ha sido criticado por varios investigadores como Iglesias de Ussel (1994), al considerar que resulta un criterio poco realista en España, donde existen una serie de factores, como la prolongación de los estudios, la difícil inserción en el mercado laboral y la crisis de la vivienda, que dificultan la emancipación de los hijos/as, haciendo que éstos dependan de sus progenitores hasta edades cada vez más tardías. En base a esta argumentación, los investigadores aconsejan elevar la edad límite hasta los 25-26 años, o considerar que dicha dependencia se extenderá, como norma, hasta los 18-21 años, salvo que los hijos/as estén estudiando, en cuyo caso, el límite se elevaría hasta los 25-26 años. Se observa que ninguna de las definiciones legales contempla estas opciones, cometiendo otro error conceptual. Lo que señalan algunas, concretamente en las leyes $12 / 2006,1 / 2007,6 / 2008$ y $19 / 2010$, es que también se considerará dependiente al hijo/a que, siendo mayor de edad, sea discapacitado. En el ámbito científico es común incluir este aspecto, fijando unos límites, en base al grado de discapacidad, a partir de los cuales el hijo/a es considerado dependiente. En términos generales, lo que normalmente se tiene en cuenta es que esa discapacidad le impida trabajar.

La definición que ofrece el Principado de Asturias (Ley 6/2008), además de la edad y la posible discapacidad, establece como criterio para determinar la dependencia de los hijos/as su situación económica. En concreto, apunta que los descendientes no tendrán rentas anuales superiores a los 8.000 euros. Este tipo de criterios de carácter económico son útiles y suelen emplearse en las definiciones académicas, aunque normalmente como complementarios a la edad. Cuando se utilizan, se considera que el hijo/a es dependiente de su padre o madre si percibe unos ingresos inferiores a una determinada cantidad, que suele fijarse en el salario mínimo interprofesional vigente.

Otro criterio comúnmente utilizado en el ámbito académico para determinar el grado de dependencia de los hijos/as es su estado civil. Se consideran dependientes todos aquellos que, siendo solteros, conviven junto al progenitor encargado del grupo monoparental. No obstante, se recomienda incluir otros elementos, por ejemplo, vinculados con la edad, para evitar caer en errores de imprecisión teórica. Se observa que ninguna de las definiciones legales hace referencia al estado civil de los hijos/as.

En algunos casos, y a pesar de los errores que puedan originar, las definiciones académicas entienden que la mera presencia de hijos/as en una familia encabezada por un solo progenitor será causa suficiente para que el grupo pertenezca a la categoría monoparental. Esto sucede también con las definiciones legales que se ofrecen a nivel estatal. Como argumento, se suele apuntar que el hecho de que los hijos/as vivan en el hogar ya implica su dependencia, lo que, según apunta Iglesias de Ussel (1994), es cuestionable, ya que los hijos/as viven en casa de sus ascendientes hasta edades cada vez más tardías aún siendo económicamente independientes. Por lo tanto, se recomienda incluir en las definiciones elementos objetivos que determinen la dependencia de esos hijos/as.

\section{Otros criterios para incluir en la explica- ción legal de monoparental}

La mayoría de definiciones legales entienden que la presencia de un único progenitor y los hijos/as dependientes son los dos aspectos claves para determinar cuándo el grupo familiar es monoparental. Junto a esto, es recomendable incorporar otros elementos, que permitan concretar aún más el significado real del término. Algunos son los siguientes:

\subsection{Motivos que generan la entrada en una situación de monoparentalidad}

Son numerosas las causas que pueden provocar una familia monoparental. De todas las clasificaciones que se han elaborado, la más completa es la que ofrece Iglesias de Ussel (1988, pp. 2840), quien identifica una docena de causas, agrupadas en cuatro categorías:

a) Monoparentalidad vinculada a la natalidad: las madres solteras.

b) Monoparentalidad vinculada a la relación matrimonial: abandono de la familia; anulación del matrimonio; separación de hecho; separación legal; divorcio; viudedad. 
c) Monoparentalidad vinculada al ordenamiento jurídico: adopción por solteras/os.

d) Monoparentalidad vinculada a situaciones sociales: emigración; trabajo de la pareja en localidades distintas; hospitalización prolongada; encarcelación.

El elevado número de situaciones, a las que hace referencia Iglesias de Ussel, ponen de manifiesto, como él mismo señala, que la homogeneidad que el concepto insinúa no existe en realidad. De hecho, son varios los expertos que plantean la inoperatividad de utilizarlo, ya que las circunstancias de cada familia monoparental, en base a la causa que ha originado la falta de un progenitor, son bastante particulares. Por eso, en el ámbito legal, sería recomendable tener en cuenta los numerosos motivos que pueden generar una situación monoparental, así como la pluralidad de formas familiares que se agrupan bajo esta categoría. Esto permitiría, por una parte, plantear medidas generales que beneficiaran a todas las familias monoparentales en su conjunto, $y$, por otra, medidas específicas que sirvieran de apoyo para cada tipo en concreto. Esto no sólo resultaría más eficaz en materia de protección social, sino que también daría una mayor visibilidad legal y social a la pluralidad de formas familiares que se agrupan bajo este término. $\mathrm{Pu}$ mar Beltrán, Bolancel Ferrer, Fargas Fernández, Navarro Michel y Reinhard (2009) apuntan, precisamente, que el problema de fondo no radica tanto en la falta de una definición común y unitaria, sino en la comprensión de que dentro de un mismo término se incluyan formas de convivencia familiar tan diversas, y con necesidades tan dispares.

\subsection{Aspectos que provocan la salida de una situación de monoparentalidad}

Para que la definición de monoparental sea precisa, se recomienda incluir también qué aspectos hacen que el grupo familiar pierda su condición. Esto sucederá cuando alguno de los dos actores básicos, progenitor e hijo/a, pierda, al menos, una de las características que convierten al grupo en monoparental.

Con respecto al progenitor, se saldrá de una situación monoparental cuando:

a) Ambos progenitores decidan poner fin a la separación conyugal de hecho, o no continuar con los trámites del divorcio o de la separación legal, retomando de esta manera la convivencia conjunta;

b) El progenitor que ha abandonado la familia regrese a la misma;

c) La causa social que ha provocado la separación entre cónyuges desaparezca o alcance su fin, como sucede cuando se sale del hospital tras una prolongada estancia en él, se obtiene la libertad tras un ingreso en prisión, o cuando todo el grupo familiar consigue reunirse en una misma ciudad, estableciendo en ella su hogar definitivo;

d) El progenitor al frente del grupo decida constituir un núcleo conyugal junto a su nueva pareja sentimental;

e) El único progenitor que se encuentra en el grupo fallezca.

En relación al hijo/a, la estructura dejará de ser monoparental cuando:

a) Cese su presencia, bien porque se ha trasladado a vivir junto al otro progenitor, bien porque se ha instalado en un hogar propio o bien porque ha fallecido;

b) Deje de ser dependiente de acuerdo con los criterios que se establezcan en la definición. Por ejemplo, cumplir una determinada edad, contraer matrimonio, encontrar un trabajo en el que se perciban unos ingresos superiores a una cantidad, etc.

\subsection{Tiempo necesario de ausencia de uno de los progenitores}

Investigadores, como Iglesias de Ussel (1988), plantean la importancia que tiene, en la conceptualización de la monoparentalidad, reflexionar acerca de cuánto tiempo ha de durar la falta de convivencia entre la pareja para que se inicie la fase monoparental. La realidad teórica carece de reflexiones al respecto pero, como añade Iglesias de Ussel, este elemento debería ser considerado crucial en la naturaleza de los grupos monoparentales.

En el ámbito legal sería un aspecto a tener en cuenta en las definiciones, pues se evitaría conceder la característica de monoparental a familias que realmente no lo son. Por ejemplo, determinados progenitores, para conseguir algún tipo de beneficio, como pueden ser los ya citados puntos que se conceden a las familias monopa- 
rentales al solicitar el ingreso de los hijos/as en un centro escolar, inician los trámites de divorcio para simular, de esta manera, ser monoparentales. Una vez que el niño/a está aceptado, se anulan esos trámites y no se continúa con el proceso de divorcio o separación legal, cometiendo un claro fraude, que las comunidades autónomas castigan relegando al último puesto de la lista al niño/a. Si en estos casos se estableciera algún tipo de requisito vinculado con este aspecto, como por ejemplo la necesidad de que haya trascurrido un determinado período de tiempo desde el inicio de los trámites del divorcio o de la separación y el momento en el que se solicita el beneficio o la ayuda social, se evitarían, o al menos se dificultarían, este tipo de fraudes a la administración pública y el perjuicio que se produce a otras familias que sí son monoparentales en realidad. Igualmente, sería prudente revisar de manera periódica la condición de la familia, ya que la monoparentalidad no es un estado permanente que dure para siempre. Por el contrario, puede cambiar, dada la naturaleza dinámica que caracteriza a esta institución.

\section{Conclusiones y discusión}

A través del análisis sociojurídico realizado se ha podido constatar que, a nivel estatal, la legislación de nuestro país no presta atención a la conceptualización de la monoparentalidad. De hecho, apenas existen normas en las que se incluya una definición de este tipo de familia. El legislador deja en manos de las comunidades autónomas esta labor; ellas son las que, tomando el legado, ofrecen en sus respectivos ordenamientos una definición, que en ocasiones resulta ambigua, como se ha podido comprobar. Esto da lugar a un escenario, en materia de Política Social, caracterizado por una pluralidad de definiciones, en la mayoría de los casos, poco precisas sobre la condición de monoparental.

Nos encontramos así ante una paradoja: por una parte, el interés por la protección social de estas familias es cada vez mayor, como lo constata el aumento de medidas dirigidas a paliar el impacto que supone, sobre todo en términos económicos, el paso de un grupo biparental a otro monoparental. Pero, por otra parte, hay una falta de conceptualización a nivel nacional que sirva de referencia a las distintas comunidades autónomas, y dé uniformidad a las intervenciones que se realizan y a los colectivos que se atienden.

Esto explica el malestar que existe entre algunas asociaciones de familias monoparentales. Lo que estas asociaciones demandan es la elaboración, a nivel nacional, de una ley que, a semejanza de la 40/2003, de 18 de noviembre, de Protección a las Familias Numerosas (BOE núm. 277, de 19 de noviembre de 2003, pp. 40.84540.852), especifique en su texto qué se entiende por familia monoparental y cuáles son los requisitos necesarios para ostentar esta condición. Hay algunas comunidades autónomas que, a falta de esta iniciativa a nivel estatal, han decidido elaborar sus propias normas internas, con rango de decreto ${ }^{3}$. Dos ejemplos de estas iniciativas son:

- Decreto 151/2009, de 29 de septiembre, de desarrollo parcial de la Ley 18/2003, de 4 de julio, de apoyo a las familias (Diario Oficial de la Generalidad de Cataluña núm. 5.475, de 1 de octubre de 2009, pp. 73.120-73.141).

- Decreto 179/2013, de 22 de noviembre, del Consell, por el que se regula el reconocimiento de la condición de familia monoparental en la Comunitat Valenciana (Diario Oficial de la Comunitat Valenciana núm. 7.159, de 25 de noviembre de 2013, pp. 34.182-34.204).

La definición que ofrecen ambos decretos sobre familia monoparental es, en términos generales, coincidente entre sí y bastante más precisa que las acepciones revisadas hasta ahora, señal de que los poderes públicos de estas regiones se han documentado al respecto y han hecho un esfuerzo por aproximarse a la realidad que, a efectos prácticos, presentan estas familias. En ambos casos las normas contemplan, además, los mismos apartados que la ley de Protección a las Familias Numerosas, siendo éstos los siguientes:

1. Objeto de la norma, que, entre otros, es regular los requisitos para el reconocimiento $\mathrm{y}$

${ }^{3}$ Como tienen ese rango normativo, no figuran en la base de datos con la que se ha trabajado. Recordemos que la base datos utilizadoa recoge la legislación vigente consolidada que figura en el Boletín Oficial del Estado (BOE). 
acreditación de la condición de familia monoparental.

2. Concepto general de familia monoparental, señalando que ésta puede ser de distinta naturaleza en función de la causa que la ha originado. Las dos normas contemplan los tipos que existen, por viudedad, abandono, ruptura conyugal, acogimiento, etc., aunque ninguna termina de recoger todas las opciones posibles. Por ejemplo, la normativa de Valencia no hace referencia a la monoparentalidad vinculada a situaciones sociales, mientras que la de Cataluña no menciona de forma expresa a las familias en las que los hijos/as sólo están reconocidos legalmente por uno de los progenitores, como sucede en los casos de adopción o reproducción asistida. Sería necesario, como ya se ha indicado, que las normas contemplaran todos los motivos que dan lugar a una situación monoparental.

3. Requisitos específicos que, tanto los hijos/as como el progenitor, deben cumplir. Con respecto a los primeros, además de la necesaria convivencia con el ascendiente, se fijan unos criterios de edad y situación económica para determinar su dependencia. Ambos decretos plantean que los hijos/as deben ser menores de 21 años, edad que se amplía hasta los 25 años, si están cursando estudios reglados. Además, no pueden percibir unos ingresos anuales superiores al indicador de renta de suficiencia (IRSC), en el caso de Cataluña, y al indicador público de renta de efectos múltiples (IPREM), en la comunidad valenciana. Las normas contemplan también la posibilidad de que sean hijos/as dependientes por discapacidad.

En lo que se refiere al progenitor, no son tan precisas en los requisitos que éste debe cumplir. Sólo apuntan, a lo largo del decreto, la necesidad de que no contraiga matrimonio o constituya una unión de hecho de acuerdo con la legislación civil. Este requisito es un tanto ambiguo y puede generar confusión porque ¿qué sucede cuando la relación y la convivencia no están reguladas legalmente? Sería, por lo tanto, necesario matizar aún más este aspecto, dedicándole la importancia que tiene. Las dos normas contemplan, además, la necesidad de que los miembros de la unidad familiar residan en la comunidad pertinente, e indican que se perderá la condición de mono- parental cuando el grupo deje de cumplir alguno de los requisitos.

Se observa que ambas definiciones se aproximan bastante a la concepción real de familia monoparental, si bien es aconsejable seguir depurándolas. Junto a las mejoras ya señaladas, habría que indicar el tiempo necesario de ausencia del progenitor no conviviente, matizar, aún más, los aspectos que generan la salida de la situación de monoparentalidad y aclarar la posible presencia de otras personas, como la familia extensa, amigos, etc., en la vivienda, distinguiendo, incluso, como se hace en el ámbito científico, entre monoparentalidad simple y compleja. El decreto de Cataluña parece referirse a este aspecto en el artículo 4.2, pero no lo hace de forma contundente.

4. Categorías de familias monoparentales, distinguiendo entre generales y especiales, como se hace con las familias numerosas. Como aspecto a destacar, los decretos no conceptualizan de igual forma uno y otro tipo de familia.

5. Procedimiento a seguir para solicitar el título de familia monoparental. Dicho trámite, así como la validez del título, no es coincidente entre las dos comunidades, aunque la condición de monoparental sí está sujeta a una revisión periódica en ambos casos.

Como valoración general del análisis concluimos que, en un país democrático como el nuestro, en el que uno de cada diez hogares son monoparentales según la Encuesta Continua de Hogares de 2014, no pueden existir tantas imprecisiones y discrepancias entre territorios y rangos normativos al clarificar qué es una familia monoparental. Si realmente se desea ofrecer una protección integral a estas familias como exige la Constitución en su artículo 39, el legislador estatal debería tomar nota de las iniciativas que se están desarrollando a nivel autonómico. Elaborar una ley nacional de familias monoparentales, como piden las asociaciones, daría uniformidad al trato y apoyo social que se dispensa, además de que permitiría una regulación legal de su condición, y un mayor control a través de los carnets/títulos de familias monoparentales. Falta saber si al legislador le interesa dar, en efecto, una respuesta integral y eficiente a los problemas que presentan estas familias. 


\section{Referencias bibliográficas}

Almeda, E., Batalla, E., Camps, C., Collado, A., Di Nella, D. y Obiol, S. (2010). Responsabilidad parental y monoparentalidad: análisis sociojurídico. En FES, España: Treinta años de sociedad, treinta años de sociología. X Congreso Español de Sociología. Pamplona: julio.

Almeda, E. y Di Nella, D. (dirs.) (2011). Las Familias Monoparentales a debate. Barcelona: Copalqui Editorial.

Avilés, M. (2013). Origen del concepto de «monoparentalidad». Un ejercicio de contextualización sociohistórica. Papers. Revista de Sociología, 98, 263-285.

Avilés, M. (2015). La monoparentalidad masculina en España. Madrid: Centro de Investigaciones Sociológicas (CIS).

Barrón, S. (2002). Familias monoparentales: un ejercicio de clarificación conceptual y sociológica. Revista del Ministerio de Trabajo y Asuntos Sociales, 40,13-30.

Fernández Cordón, J.A. y Tobío Soler, C. (1998). Las familias monoparentales en España. Revista Española de Investigaciones Sociológicas, 83, 51-85.

Fernández Cordón, J.A. y Tobío Soler, C. (1999). Las Familias Monoparentales en España. Madrid: Ministerio de Trabajo y Asuntos Sociales.

Flaquer, Ll.; Almeda, E. y Navarro-Varas, L. (2006). Monoparentalidad e Infancia. Barcelona: Fundación La Caixa, Colección de Estudios Sociales, 20.

Iglesias de Ussel, J. (1988). La situación de la familia en España y los nuevos modelos familiares. En J. Iglesias de Ussel (Ed.), Las Familias monoparentales (pp. 23-40). Madrid: Instituto de la Mujer, Ministerio de Asuntos Sociales.

Iglesias de Ussel, J. (1994). La familia. En V Informe Sociológico sobre la situación social en España, 1 (pp. 415-547). Madrid: Fundación FOESSA.

Iglesias de Ussel, J. (1998). La familia y el cambio político en España. Madrid: Editorial Tecnos.

Pumar Beltrán, N., Bolancel Ferrer, J., Fargas Fernández, J., Navarro Michel, M. y Reinhard, J. (2009). La revisión de la protección de las familias monoparentales por parte de la Seguridad Social. Madrid: Secretaría de Estado de Seguridad Social.

Rodríguez, C. y Luengo, T. (2003). Un análisis del concepto de familia monoparental a partir de una investigación sobre núcleos familiares monoparentales. Papers. Revista de Sociología, 69, 59-82.

Rodríguez, C. y Luengo, T. (2011). Una lectura de la monoparentalidad desde la perspectiva de la posmodernización de la familia. En E. Almeda y D. Di Nella (dirs.), Las Familias Monoparentales a debate, 3 (pp.55-84). Barcelona: Copalqui Editorial.

Roll, J. (1991). One in ten: lone parent families in the European Community. En N. Manning (ed.), Social Policy Review 1990-1991 (pp. 169-186). Great Britain: Longman Group.

Vela, A. J. (2005). Propuestas para una protección integral de las familias monoparentales. La Ley: Revista jurídica española de doctrina, jurisprudencia y bibliografia, 5,1.391-1.402. 